\title{
Izboljševanje poslovanja s pomočjo modela poslovne odličnosti
}

\author{
UDK: 352.001:7:65.011.8
}

\author{
Tomislav Nemec \\ Upravna enota Ljutomer \\ tomi.nemec@gov.si
}

\begin{abstract}
IZVLEČEK
V prizadevanjih za kakovost in odličnost uporablja javna uprava podobne modele kot gospodarstvo. V letu 2004 je bil prvič uporabljen tudi model poslovne odličnosti (PRSPO). Vsak model koristi organizaciji le toliko, kolikor ji uspe z njegovo pomočjo dejansko izboljšati poslovanje. Za sprejemanje učinkovitih ukrepov za izboljšave pa so potrebne nove ideje in inovacijsko okolje, kar je izziv za javno upravo. $V$ osrednjem delu članka so predstavljeni rezultati in nekatera vprašanja $v$ zvezi z pilotnim projektom PRSPO, v nadaljevanju pa nekatere prednosti in priložnosti za izboljšanje poslovanja, ki so jih ugotovili zunanji ocenjevalci, oziroma primeri dobre prakse trenutno najboljših. Predstavljeni so tudi ukrepi, ki jih je ena izmed upravnih enot predvidela kot posledico uporabe modela poslovne odličnosti. Prispevek se zaključuje s predstavitvijo treh organizacijsko upravljavskih izzivov za menedžment $v$ javni upravi.
\end{abstract}

Ključne besede: poslovna odličnost, kakovost, javna uprava, pilotni projekt PRSPO, ukrepi, izboljšave

\section{Uvod}

Doseganje odličnosti v proizvodnji, storitvah ali v odnosih s strankami je doživetje, ki ne pusti ravnodušnega nikogar, še posebej, če gre za lastno izkušnjo, ko imamo priložnost uporabiti odličen izdelek ali doživeti izredno kakovostno storitev. Že koren same besede "odličnost« nam pove, da gre za nekaj, kar je »od lika«, nekaj, kar je bistveno več od povprečja, v primeru kakovosti je torej to kakovost $\vee$ najvišji možni meri. Odličnost je danes samoumeven cilj najbolj razvitih, kakovost pa je le izhodišče za odličnost.

Najboljši si prizadevajo, da svoje stranke navdušijo, pozitivno presenetijo, da jim ponudijo več, kot so pričakovale. Tudi država, ki je odgovorna za splošno blaginjo in kakovost življenja na svojem teritoriju, tu ne sme biti izjema. Slovenija si 
Tomislav Nemec

\section{Izboljševanje poslovanja s pomočjo}

modela poslovne odličnosti

mora kot nova članica EU zadati višje cilje kot doslej, ne le dosegati povprečje razvitosti znotraj EU, ampak ga preseči in postati ena izmed npr. petih najbolj razvitih njenih članic. Javna uprava, kot največje »podjetje« v državi, mora za podporo tega cilja tudi sama postati ena najboljših $\vee$ EU. Čas je, da si tudi država prizadeva za poslovno odličnost. Ambicije javne uprave morajo postati mnogo višje, preseči morajo splošna pričakovanja, javna uprava pa mora postati nadpovprečno učinkovit del družbe in spodbujevalec razvoja. Njen cilj morajo biti storitve, ki bodo navduševale njene odjemalce, storitve, ki bodo ne samo izpolnile, ampak tudi presegle pričakovanja strank glede strokovnosti, učinkovitosti in odzivnosti. S svojim zgledom mora država soustvarjati stimulativno okolje, v katerem bodo "dobri« lažje postajali "odlični« in "odlični« lažje postali "zmagovalci» tudi v evropskem merilu. ${ }^{1}$

\section{Prizadevanja za kakovost in odličnost $v$ javni upravi}

$\checkmark$ zadnjih letih lahko tudi $v$ javni upravi opazimo kar nekaj prizadevanj posameznih organov, da bi poslovali kakovostno, postali čim uspešnejši (poslovno odlični) in da bi $\vee$ največji meri zadovoljili svoje deležnike oziroma vse zainteresirane strani (državljane, vlado, zaposlene, demokratično javnost...). Kakovost $v$ slovenski javni upravi je eno izmed redkih področij, ki se lahko pohvali z mednarodnimi standardiziranimi sistemi vodenja, kot so na primer $\mathrm{ISO}^{\mathbf{2}}, \mathrm{CAF}^{\mathbf{3}}$ in EFQM (PRSPO) ${ }^{\mathbf{4}}$. Samo dejstvo, da je upravna organizacija uvedla katerega izmed modelov vodenja, pa deležnikom pomeni le toliko, kolikor tudi sami "začutijo" neposredno korist. Modeli so namreč le osnova, napolniti jih je treba z dobrimi praksami in pristopi ter doseči cilj: dobre (odlične) rezultate na vseh področjih.

Mnogi se sprašujejo, kateri model je boljši in bolj primeren za posamezno dejavnost ali organizacijo. Ob podrobnejšem poznavanju modelov in z vidika

\footnotetext{
1 Med finaliste za Priznanje Republike Slovenije za poslovno odličnost za leto 2005, oziroma v ožji izbor za priznanje, so se (po kategorijah) uvrstile štiri organizacije. Odbor za priznanja med njimi ni prepoznal nobene organizacije, ki bi ustrezala visokim kriterijem PRSPO, zato je odbor sklenil, da se PRSPO za leto 2005 ne podeli.

2 International Organizaton for Standardization

3 Common Assessment Framework, ki je v slovenščino preveden kot Evropski okvir za ocenjevanje kakovosti v javnem sektorju.

4 European Foundation for Quality Management. Kot promocijsko orodje je ta sklad leta 1991 ustanovil nagrado za poslovno odličnost EQA - European Quality Award. Slovenska različica te nagrade je Priznanje Republike Slovenije za poslovno odličnost - PRSPO.
} 
celovitega vodenja kakovosti (TQM) ugotovimo sorodnost modelov, opazimo lahko ponavljanje ključnih besed ter sovpadanje njihovih temeljnih gradnikov, to je obvladovanje izboljševanja, procesni pristop ter usmerjenost na odjemalce in rezultate. Model posamezni organizaciji koristi le toliko, kolikor ji zagotavlja uspešno udejanjanje strategije, to pa je mogoče le, če je intenzivno vpeljan v vse nivoje in če ga razumejo vsi zaposleni. Da se pa sistem zares ukorenini v organizacijo, sta potrebni vsaj dve leti (Ložar, 2003).

$\checkmark$ slovenski javni upravi je bilo doslej podeljenih cca 40 certifikatov vodenja kakovosti ISO 9001:2000 ter izvedenih približno enako število samoocenjevanj po modelu za javni sektor CAF, mnogi med njimi pa so uporabniki obeh navedenih modelov. V letu 2004 pa je prvič razpisan pilotni projekt PRSPO za javno upravo.

Vprašanja, ki se večkrat porajajo ob uvajanju navedenih modelov, so: ali organizacije $v$ resnici pridobijo toliko, kot se pričakuje, ali pa so bila pričakovanja morda pretirana? Ali je dodana vrednost uvedbe modela sploh ovrednotena in sprejemljiva glede na stroške vzpostavitve in vzdrževanja? Kako uvedeni model dejansko vpliva na zadovoljstvo uporabnikov, zaposlenih in na druge rezultate poslovanja? Doslej je bilo opravljenih nekaj raziskav glede koristi in vplivov posameznih modelov predvsem $\vee$ gospodarstvu ${ }^{\mathbf{5}}$ manj pa $\vee$ javni upravi. Modela ISO in CAF sta $v$ javni upravi $v$ uporabi že dalj časa, zato se $v$ nadaljevanju članka osredotočamo na prve izkušnje javne uprave s poslovno odličnostjo oziroma z uporabo modela PRSPO.

\section{Poslovna odličnost in model EFQM (PRSPO)}

Izraz "poslovna odličnost» še vedno ni jasno definiran, niti nima svoje filozofije in načel. Različni avtorji ga različno definirajo. Tako Dale in Lascelles definirata odličnost kot neopredeljiv cilj, ki sloni na nekih dogovornih merilih. Drugi menijo, da je odličnost le določena stopnja TQM. Definicija odličnosti, ki jo je postavila EFOM, pravi, da je odličnost »izstopajoča praksa v upravljanju organizacije in doseganju rezultatov «. Marolt in Gomišček definirata odličnost kot "preseganje povprečja in iskanje najboljšega možnega, tako glede zadovoljstva kupcev, učinkovitosti virov, varovanja okolja kot tudi glede poslovnih rezultatov organizacije» (Marolt, Gomišček, 2005).

Doseganje poslovne odličnosti ni le abstraktna teorija; to so konkretni dosežki pri tem, kaj organizacija dela, kako dela in kakšne rezultate dosega, ter prepričanje, da bo takšne rezultate trajno dosegala $\vee$ prihodnje. Poslovna

5 Pivka M., Uršič D. (1999): „ISO 9000 in konkurenčnost podjetij - slovenske izkušnje«, Zbornik referatov SZK 8. letna konferenca, Ljubljana, str. 87-88 
Tomislav Nemec

\section{Izboljševanje poslovanja s pomočjo}

modela poslovne odličnosti

odličnost tako ni program ali sistem, je način poslovanja. Slovenska fundacija za poslovno odličnost na svoji spletni strani opredeljuje poslovno odličnost z naslednjimi trditvami ${ }^{\mathbf{6}}$ :

- Poslovna odličnost je zbirka učinkovitih orodij in konceptov, ki so se dokazano izkazali v praksi.

- Poslovna odličnost je določena z zadovoljstvom in navdušenjem kupcev.

- Poslovna odličnost vključuje tako proces neprestanega izboljševanja kot tudi prelomne dogodke, ki pomenijo radikalne izboljšave.

- Orodja in tehnike poslovne odličnosti so uporabni pri vseh vidikih poslovanja.

- Poslovna odličnost pomeni odličnost delovanja organizacije. Vse kar je manj, pomeni priložnost za izboljšave.

- Poslovna odličnost zvišuje zadovoljstvo kupcev, skrajšuje poslovni cikel ter zmanjšuje stroške, napake in popravila.

- Poslovna odličnost ni uporabna samo v gospodarskih organizacijah. Deluje tudi v neprofitnih organizacijah, npr. v šolah, pri socialnih storitvah, vladnih ustanovah.

- Rezultati (nefinančni in finančni) so naravna posledica učinkovitega upravljanja poslovne odličnosti.

Sam model in njegova shema podrobneje predstavljena $v$ številni strokovni literaturi, zato $v$ nadaljevanju navajamo le nekaj osnovnih podatkov. Model je nastal pod vodstvom European Foundation for Quality Management (EFQM), ki jo je ustanovilo 14 vodilnih evropskih podjetij. Organizacijo lahko ocenijo zunanji ocenjevalci ali pa se oceni sama, in sicer tako, da za vsako merilo ugotovi, do katere stopnje izpolnjuje zahteve modela. Ocena v točkah (skupaj jih je možno 1000) pokaže, kako daleč je prišla organizacija na poti $v$ odličnost. Tako se vsako leto ocenjujejo in med seboj primerjajo najboljša evropska podjetja ter potegujejo za evropsko nagrado, ki se podeljuje $v$ Bruslju. Rezultat 1000 točk je zgolj teoretičen, saj idealnih podjetij ni, najbolj odlična evropska podjetja, kot so na primer Siemens in Nokia, so zbrala cca 700 točk, v letu 2005 pa se jim je zelo približala tudi Luka Koper, ki je prejela evropsko priznanje "Recognised for Excellence« in bila uvrščena v razred med 601 in 650 točk. $\checkmark$ Sloveniji se model uporablja na podlagi zakona $\vee$ obliki Priznanja Republike Slovenije za poslovno odličnost (PRSPO), ki se vsako leto podeli najboljšemu podjetju.

6 http://www.sfpo.org/ 
Model EFQM je referenčna točka za dobro upravljavsko prakso in dolgoročni trajnostni razvoj. Model temelji na devetih merilih, uravnoteženo porazdeljenih med dejavnike in rezultate. Dejavniki vplivajo na rezultate, ki so vidni sadovi dela (dejavniki $\rightarrow$ "setev", rezultati $\rightarrow$ "žetev«). Pet od t.i. "dejavnikov«, zajema aktivnosti in napore organizacije, odgovore na "kaj" in "kako". Preostala štiri merila, t.i. "rezultati«, pa zajemajo rezultate in dosežke organizacije. Oboji so med seboj povezani: " rezultati« so posledica " dejavnikov", " dejavniki " pa se izboljšujejo s pomočjo povratnih informacij iz »rezultatov«.

Z uporabo procesa, ki ga model EFOM imenuje samoocenjevanje, si organizacije lahko vsak trenutek ustvarijo celovito sliko svojega stanja. Ta slika, ki daje dragocene povratne informacije o uspešnosti pristopa organizacije $v$ vseh njenih aktivnosti, je lahko močno gibalo izboljšav. $V$ procesu samoocenjevanja tako organizacija spozna (EFQM, 2004):

- svoje prednosti in področja za izboljšanje,

- kako daleč na poti odličnosti je že in kako daleč naprej naj še gre,

- kje je v primerjavi z drugimi,

- $\quad v$ kaj naj usmeri svoje omejene vire, da bo od njih korist čim večja.

\section{Pilotni projekt PRSPO za javno upravo}

V pilotnem projektu PRSPO za javno upravo je sodelovalo 14 upravnih organizacij (13 upravnih enot in ena policijska uprava). Z izvedbo pilotnega projekta PRSPO so bile tako prvič podeljene neodvisne zunanje ocene poslovanja organov javne uprave, kar omogoča objektivno primerjanje njene uspešnosti z gospodarstvom. Organizacije so $v$ samoocenitveni vlogi (35 strani) na osnovi pristopa RADAR (Results - rezultati, Approach - pristop, Deployment - razširjenost pristopa, Assessment - ocenjevanje in Review - pregled) temeljito analizirale svoje poslovanje z vidikov devetih meril in njihovih podmeril.

Pogoj za sodelovanje v projektu je bil pridobljeni standard kakovosti ISO ali vsaj izvedena samoocena po modelu CAF. Predvsem prijavitelji, ki so pred tem naredili tudi samooceno po modelu CAF, so tako dobili prvi celovitejši "vtis « o svojem poslovanju, saj so iz ocen zunanjih ocenjevalcev lahko preverili, ali so bili pri samooceni po modelu CAF objektivni in ali so pravilno ugotovili svoje prednosti in pomanjkljivosti. Doseženi rezultati ${ }^{7}$ so bili relativno dobri, saj sta bili najboljši upravni enoti uvrščeni v razred 301-400 točk, večina prijaviteljev

7 Vir: Vlada RS, Odbor za priznanja RS za poslovno odličnost (2005), „Končno poročilo prijavitelju - UE Ljutomer«, Urad za meroslovje, Ljubljana. 
Tomislav Nemec

Izboljševanje poslovanja s pomočjo

modela poslovne odličnosti

$(57,1 \%)$ pa je bila $v$ razredu 201-300 točk, kar je glede na rezultate dosedanjih pilotnih projektov zelo dober rezultat.

Preglednica 1: Število organizacij v posameznih razredih glede na končno število točk

\begin{tabular}{|c|c|c|c|c|c|c|c|c|c|c|}
\hline razred & $\frac{8}{\frac{8}{0}}$ & \begin{tabular}{l}
8 \\
\multirow{N}{*}{} \\
$\frac{1}{0}$
\end{tabular} & 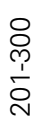 & $\begin{array}{l}\text { o } \\
\text { ț } \\
\text { ò }\end{array}$ & $\begin{array}{l}\text { Oे } \\
\text { م) } \\
\frac{1}{q} \\
\dot{q}\end{array}$ & 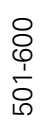 & $\begin{array}{l}8 \\
\frac{1}{1} \\
0 \\
0\end{array}$ & $\begin{array}{l}8 \\
\infty \\
\infty \\
1 \\
\vdots\end{array}$ & $\begin{array}{l}\circ \\
\text { ㅁ } \\
\frac{1}{1} \\
\infty \\
\infty\end{array}$ & $\frac{8}{\frac{8}{\frac{1}{8}}}$ \\
\hline $\begin{array}{l}\text { število } \\
\text { organizacij }\end{array}$ & 0 & 4 & 8 & 2 & 0 & 0 & 0 & 0 & 0 & 0 \\
\hline
\end{tabular}

Preglednica 2: Odstotkovni deleži prijaviteljev v $10 \%$ pasovih glede na možno število točk po posameznih merilih

\begin{tabular}{|c|c|c|c|c|c|c|c|c|c|c|c|c|}
\hline \multirow{2}{*}{\multicolumn{2}{|c|}{ dejavnik / rezultat }} & \multicolumn{10}{|c|}{ pasovi ocen $\vee \%$} & \multirow{2}{*}{$\begin{array}{l}\bar{\pi} \\
\frac{2}{3} \\
\frac{\vec{v}}{\omega}\end{array}$} \\
\hline & & م & 요 & ○े & ○ & $\circ$ & 8 & 요 & ○ & ৪ & ᄋ & \\
\hline 1. & voditeljstvo & 0,0 & 35,7 & 57,1 & 0,0 & 7,1 & 0,0 & 0,0 & 0,0 & 0,0 & 0,0 & 100,0 \\
\hline 2. & $\begin{array}{l}\text { politika in } \\
\text { strategija }\end{array}$ & 7,1 & 28,6 & 42,9 & 21,4 & 0,0 & 0,0 & 0,0 & 0,0 & 0,0 & 0,0 & 100,0 \\
\hline 3. & zaposleni & 0,0 & 14,3 & 78,6 & 7,1 & 0,0 & 0,0 & 0,0 & 0,0 & 0,0 & 0,0 & 100,0 \\
\hline 4. & $\begin{array}{l}\text { partnerstva } \\
\text { in viri }\end{array}$ & 7,1 & 28,6 & 57,1 & 7,1 & 0,0 & 0,0 & 0,0 & 0,0 & 0,0 & 0,0 & 100,0 \\
\hline 5. & procesi & 7,1 & 21,4 & 57,1 & 14,3 & 0,0 & 0,0 & 0,0 & 0,0 & 0,0 & 0,0 & 100,0 \\
\hline 6. & $\begin{array}{l}\text { rezultati v zvezi } \\
\text { z odjemalci }\end{array}$ & 7,1 & 35,7 & 21,4 & 35,7 & 0,0 & 0,0 & 0,0 & 0,0 & 0,0 & 0,0 & 100,0 \\
\hline 7. & \begin{tabular}{|l} 
rezultati v zvezi \\
z zaposlenimi
\end{tabular} & 0,0 & 50,0 & 35,7 & 14,3 & 0,0 & 0,0 & 0,0 & 0,0 & 0,0 & 0,0 & 100,0 \\
\hline 8. & $\begin{array}{l}\text { Rezultati v zvezi } \\
\text { z družbo }\end{array}$ & 28,6 & 42,9 & 21,4 & 7,1 & 0,0 & 0,0 & 0,0 & 0,0 & 0,0 & 0,0 & 100,0 \\
\hline 9. & $\begin{array}{l}\text { Ključni rezultati } \\
\text { delovanja }\end{array}$ & 14,3 & 42,9 & 42,9 & 0,0 & 0,0 & 0,0 & 0,0 & 0,0 & 0,0 & 0,0 & 100,0 \\
\hline
\end{tabular}


Pregled doseženih rezultatov pri posameznih dejavnikih in merilih kaže, da je bil najboljši rezultat dosežen pri dejavniku "Voditeljstvo", kjer noben prijavitelj ni v najnižjem razredu 0-10\% možnih točk, večina jih je $v$ razredu $21-30 \%$ točk, en prijavitelj pa je bil uvrščen $v$ razred $41-50 \%$ točk. Najslabša rezultata sta bila dosežena pri »Rezultatih v zvezi z družbo«, kjer je bilo $28,6 \%$ prijaviteljev uvrščeno $\vee$ najnižji razred $0-10 \%$ točk in le en prijavitelj $\vee$ razred $31-40 \%$ točk, ter "Ključnih rezultatih delovanja», kjer je 14,3\% prijaviteljev bilo uvrščeno v najnižji razred 0-10\% točk, nobenemu pa se ni uspelo uvrstiti v razred nad 30\% možnih točk.

Pilotni projekt PRSPO je priložnost, da bi se naredila celovita vsebinska analiza (ki bi jo koordinirala MJU in Urad za meroslovje) ter pripravil ustrezen nabor priporočil in smernic, ki bi lahko obogatile in dale novo vsebino $v$ prizadevanjih za modernizacijo javne uprave. $V$ projektu so sodelovale večinoma tiste upravne enote in ena policijska uprava, ki so že doslej dosegale dobre poslovne rezultate in $z$ lastnimi rešitvami prispevale $k$ oblikovanju dobrih praks znotraj javne uprave, zato bi bilo smiselno narediti analizo njihovega poslovanja $\checkmark$ dveh smereh, in sicer proučitev prepoznanih prednosti (vzpostavljenih dobrih praks) ter proučitev prepoznanih priložnosti za izboljšanje. $\vee$ peti točki tega članka podajamo nekaj izhodišč za tako analizo, prav tako so predstavljeni nekateri ukrepi za izboljšanje poslovanja.

\subsection{Model PRSPO in drugi sistemi vodenja kakovosti}

Izvedeni pilotni projekt PRSPO ponuja kot "stranski produkt « priložnost za razmislek tudi o dosedanjih pristopih obvladovanja kakovosti $\vee$ javni upravi, to je, ali sta bila njena dosedanja delovanja in prizadevanja "pravilna " ter so dobra osnova za razvijanje poslovne odličnosti.

Razlike med bolj uspešnimi in povprečnimi organizacijami ne določa strategija, ampak jo določajo vzpostavljeni sistemi, ki omogočajo udejanjanje strategije. Tudi v primeru pilotnega projekta PRSPO za javno upravo se je pokazalo, da organizacije z vzpostavljeni sistemi vodenja, kot npr. sistemom za obvladovanje kakovosti, vzpostavljenim sistemom za ravnanje z ljudmi, sistemom vodenja s cilji, sistemom komuniciranja z javnostmi ali obvladovanjem odnosov z uporabniki idr. lažje dosežejo nadpovprečne rezultate. Tako imata obe upravni enoti, ki sta dosegli največ točk in že nekaj let poslujeta $v$ skladu $\mathrm{s}$ standardom ISO 9001, narejeni samooceni po modelu CAF ter uporabljata tudi druge modele in pristope na različnih področjih vodenja. Vse te aktivnosti vodijo do sinergijskih učinkov in se medsebojno povezujejo $v$ modelu poslovne odličnosti EFOM. številne raziskave so namreč pokazale (Dolinšek idr., 2004), 
Tomislav Nemec

\section{Izboljševanje poslovanja s pomočjo}

modela poslovne odličnosti

da je model EFQM komplementaren z orodji, kot so Investors in people, Charter Mark, ISO in $\mathrm{BSC}^{\mathbf{8}}$, o čemer so podrobnejše informacije dostopne $v$ publikaciji " Linking the Excellence Model to other Management Models and Tools."

Predvsem so imele upravne enote, ki že nekaj let poslujejo $v$ skladu $\mathrm{s}$ standardom ISO, dobro osnovo, da so v pilotu PRSPO lahko dosegle nadpovprečne rezultate. $\vee$ teh upravnih enotah izvajajo aktivnosti, s katerimi se lažje dokazuje izpolnjevanje zahtev meril modela PRSPO. Te aktivnosti so npr.:

- izvajanje notranjih presoj,

- izvajanje vodstvenih pregledov z ustreznim planiranjem ter izvajanjem korektivnih in preventivnih ukrepov,

- obvladovanje in nenehno izboljševanje procesov,

- opredeljeno voditeljstvo, politika in strategija,

- opredeljeno obvladovanje virov,

- predvsem pa usmerjenost k odjemalcem in zaposlenim.

Dejanski vpliv sistema kakovosti ISO 9001 na oceno odličnosti in korelacija med njim ter doseženimi rezultati $v$ tem pilotnem projektu pri posameznih merilih zaenkrat nista dokazljiva, saj so informacije vezane na posameznega prijavitelja zaupne in brez njegovega dovoljenja niso na vpogled. $\vee$ zvezi s tem vprašanjem je zanimiv primer Splošne bolnišnice Novo mesto, enega izmed štirih finalistov PRSPO za leto 2005 in najuspešnejšega predstavnika javnega sektorja med prijavitelji. Bolnišnica se je po nekaj letih sodelovanja $\vee$ pilotnih projektih PRSPO za zdravstvo odločila pridobiti standard ISO 9001 predvsem zaradi ugotovitve, da je za boljše rezultate na področju odličnosti treba tudi ustrezno obvladovati procese.

Vsekakor pa lahko zaključimo, da so se v pilotnem projektu PRSPO prvič povezale vse dosedanje aktivnosti ter prizadevanja (sprejete uredbe, CAF, ISO) za kakovost, ki so bila izvedena v javni upravi, kar pomeni, da več aktivnosti v preteklosti vodi $\mathrm{k}$ boljšim rezultatom poslovne odličnosti.

\section{Izboljšanje poslovanja na podlagi zunanje ocene}

Sodelovanje v pilotnem projektu PRSPO ali zgolj samoocena organizacije daje dragocene podatke o trenutnih prednostih in možnostih za izboljšanje. Sodelujoči so dobili obširne povratne informacije, ki zajemajo vse vidike upravljanja.

8 Balanced scorecard. V Sloveniji se uporablja izraz Model uravnoteženih kazalnikov.

9 http://www.shu.ac.uk/research/integralexcellence/docs/management\%20models.pdf 
Če hočejo imeti od samoocene po modelu EFOM čim večjo korist, to ne sme biti enkraten dogodek, ki bi se končal z izdelano samooceno ali poročilom zunanjih ocenjevalcev, ampak mora preiti $v$ aktivnosti, ki se bodo planirale $v$ običajnem procesu načrtovanja poslovanja ter pozneje pregledovale na vodstvenem pregledu. Dogodek samoocene mora "odmevati« $v$ vsakdanjem delu, vse dokler ne bodo izvedeni vsi ukrepi, ki so bili sprejeti na podlagi prepoznanih priložnosti za izboljšave. "Zorenje za odličnost» je dolgoročen proces, sodelovanje $\vee$ pilotnem projektu pa le prvi korak na poti k odličnosti, saj je iz izkušenj $\checkmark$ PRSPO in EFQM znano, da organizacije potrebujejo nekaj let discipliniranega in vztrajnega učenja, veliko uvedenih izboljšav in inovacij, da lahko napredujejo na lestvici odličnosti med najboljše (v RS razred 500-600 točk).

\subsection{Nova inovacijska kultura javne uprave - pogoj za odličnost poslovanja}

Kako priti do nabora inovacij, novih predlogov, izboljšav in pravih ukrepov, ki bodo učinkoviti in bodo premaknili organizacijo za stopnico više na poti $k$ odličnosti? S temi vprašanji se ukvarja menedžment ne samo v javni upravi, ampak je to izziv tudi v drugih organizacijah. Gotovo je nekaj, in sicer, da ne moremo delati stvari tako, kot smo jih včeraj, če hočemo boljše rezultate. $S$ tem, ko je javna uprava odprla vrata poslovni odličnosti, je na neki način pokazala, da želi postati drugačna, za to pa bo potrebovala številne nove ideje, poglede in pristope. Večina inovacij lahko prihaja le od ljudi "s prve bojne črte", se pravi tistih, ki so blizu izvedbeni ravni poslovanja, tistih, ki dnevno izvajajo zakonodajo, se srečujejo s strankami, rešujejo organizacijske, kadrovske in finančne probleme. Ob tem se postavlja vprašanje, kako te ljudi motivirati za večjo kreativnost in kako zajeti ideje, ki se porajajo ob vsakodnevnem delu.

$\checkmark$ javni upravi se mora uvesti odgovornost za inovacije in pričeti z načrtnim vzpodbujanjem ustvarjalnosti in zgraditi najširše komunikacijske kanale, po katerih se bodo predstavljali vsi odprti problemi in vprašanja ter tudi predlagane rešitve. Inovacije $v$ poslovnem okolju niso plod posameznika, ampak celotnega tima in stimulativnega okolja. Ustvarjanje »inovacijske« notranje kulture postaja izziv tudi za javno upravo. Poskrbeti mora za razmere, $v$ katerih bo inovacijski proces opredeljen ter obvladovan, ustvarjalno mišljenje pa bo postalo pomembna vrednota.

$\checkmark$ javni upravi je že bilo nekaj korakov $v$ tej smeri, kot npr. zbiranje koristnih predlogov zaposlenih, ustanavljanje skupin za dobre prakse, skupin za odpravljanje administrativnih ovir. Organizirajo se konference dobre prakse, $v$ letnih poročilih se zahtevajo tudi predlogi za izboljšanje dela. Nekaj več inovativnosti se zahteva 


\section{Tomislav Nemec}

\section{Izboljševanje poslovanja s pomočjo \\ modela poslovne odličnosti}

od tistih upravnih organov, ki uporabljajo modele kakovosti, npr. ISO 9001 zahteva nenehno izboljševanje procesov, kar lahko pomeni ali reorganizacijo procesov, ali zmanjševanje časa izvedbe in stroškov. Standard zahteva tudi izvajanje notranjih presoj, ki jih upravni organi uporabljajo kot način za zagotavljanje nenehnega izboljševanja. Upravne organizacije z uvedenim sistemom kakovosti in tiste, ki pravilno in redno izvajajo samoocene po modelu CAF, so vstopile $v$ preprost a učinkovit krog kakovosti (Demingov ali P-D-C-A krog) in ga uporabljajo za svoje izboljševanje. Pilotni projekt PRSPO je pri prijaviteljih kljub temu, da so to upravne organizacije, ki že dalj časa uporabljajo katerega izmed sistemov kakovosti, odprl dileme o zadostni prisotnosti ustvarjalnosti in inovativnosti, saj $\checkmark$ svojih točkah kar na nekaj mestih zahteva dokaze o pristopu in rezultatih.

Preglednica 3: Tema ustvarjalnosti in inovativnosti v modelu EFQM ${ }^{10}$

\begin{tabular}{|c|c|}
\hline $\begin{array}{c}\text { točka } \\
\text { podmerila }\end{array}$ & tema \\
\hline 1. a & vodje spodbujajo in opogumljajo \\
\hline 2. $b$ & $\begin{array}{l}\text { uporaba rezultatov ustvarjalnosti kot vhodnih informacij za } \\
\text { politiko in strategijo }\end{array}$ \\
\hline 3. $c$ & dajanje priložnosti za ustvarjalnost in inovativnost \\
\hline 4. $a$ & $\begin{array}{l}\text { uporaba partnerstev za zavzemanje za inovativnost } \\
\text { in ustvarjalnost }\end{array}$ \\
\hline 4. e & $\begin{array}{l}\text { uporaba informacij in znanja za spodbujanje inovativnosti } \\
\text { in ustvarjalnosti }\end{array}$ \\
\hline 5. b & $\begin{array}{l}\text { uporaba inovativnosti in ustvarjalnosti udeleženih strani za } \\
\text { spreminjanje in izboljševanje procesov }\end{array}$ \\
\hline 5. $c$ & $\begin{array}{l}\text { uporaba ustvarjalnosti in inovativnosti za razvoj proizvodov } \\
\text { in storitev }\end{array}$ \\
\hline 5. e & $\begin{array}{l}\text { uporaba ustvarjalnosti in inovativnosti za izboljšanje } \\
\text { odnosov z odjemalci }\end{array}$ \\
\hline $\begin{array}{l}6 ., \\
7 ., \\
8 ., \\
9 .\end{array}$ & $\begin{array}{l}\text { merjenje uspešnosti procesov ustvarjalnosti in inovativnosti } \\
\text { (npr. inovativnosti pri načrtovanju) }\end{array}$ \\
\hline
\end{tabular}


Vse te aktivnosti so sicer koristne, vendar niso posledica sistemskega pristopa znotraj javne uprave in del ustvarjalnega sodelovanja mnogih za inovativnost dela" ${ }^{11}$, prav tako $v$ to ni dovolj vključena zainteresirana javnost, saj bi le na ta način lahko pridobili večje število invencij (novih zamisli), izmed katerih bi jih del postalo tudi resnično uporabnih in koristnih ter bi jih odjemalci sprejeli. Ustvarjanje takega okolja $\vee$ javni upravi je pogoj, da bo le-ta lahko napredovala $v$ poslovni odličnosti v višji razred od 301-400 točk in se tako pridružila najboljšim.

\subsection{Primer ukrepov na podlagi zunanje ocene}

Ocena zunanjih ocenjevalcev oziroma poročilo, ki so ga prejeli sodelujoči v pilotnem projektu, je ključna dodana vrednost in smisel sodelovanja v projektu. Kot primer navajamo, da je bilo samo za UE Ljutomer ugotovljenih 92 prednosti in kar 146 priložnosti za izboljšanje. Tako obširno poročilo je priložnost za poglobljeno analizo poslovanja, ki lahko pripelje do nabora ukrepov za postopno uvajanje $\vee$ poslovanje. Kot primer navajamo deset ukrepov, ki so posledica sodelovanja $\vee$ pilotnem projektu PRSPO in jih je UE Ljutomer dodatno predvidela $\vee$ Letnem planu 2005:

- razviti kazalnike o stopnji uravnoteženosti obremenitev,

- uvesti najmanj eno storitev izven običajnih postopkov, s katero se bo povečalo zadovoljstvo strank,

- povezati osebne cilje z organizacijskimi za upravno področje glede zaostankov in \% rešenih zadev v roku,

- povezati sistem ocenjevanja delovne uspešnosti z nenehnim izboljševanjem,

- uvesti dodaten kazalnik spremljanja odzivnosti na spremembe in novosti,

- vzpostaviti sistem merjenja učinkov sprememb organiziranosti in poslovanja,

- izvesti merjenje zadovoljstva partnerjev z delom UE (ministrstva, lokalni organi javne uprave...) in ugotoviti njihova pričakovanja,

- vzpostaviti sistem spremljanja strateških dobaviteljev (partnerjev) glede dobave storitev $v$ posameznih fazah vodenja upravnega postopka ter njihovo ocenjevanje in povratno informiranje,

- vzpostaviti register finančnih tveganj,

- spodbuditi inovativnost zaposlenih - povečati število koristnih predlogov zaposlenih in ustanoviti tim za razvoj dobrih praks.

10 Povzeto po Model odličnosti EFQM - javni in prostovoljni sektor, Urad RS za meroslovje, Ljubljana 2004.

11 Metodologija USOMID-Ekonomska fakulteta v Mariboru, dr. Matjaž Mulej, http://sl.wikipedia.org/wiki/Inovacija 
Tomislav Nemec

\section{Izboljševanje poslovanja s pomočjo}

modela poslovne odličnosti

\subsection{Prednosti in priložnosti izboljšanja na podlagi zuna- njih ocen}

Da bi spodbudili komunikacijo in med seboj izmenjali vsaj nekaj ključnih ugotovitev iz posameznih poročil zunanjih ocenjevalcev, je bila $\vee$ juliju 2005 izvedena anketa med vsemi sodelujočimi $v$ pilotnem projektu PRSPO. Na anketo se je odzvalo 7 upravnih enot in ena policijska uprava (cca 60\% vseh udeležencev projekta). Organizacije so odgovarjale na tri ključna vprašanja ankete, in sicer:

- Katere (vsaj tri) ugotovljene prednosti v poročilu so njihove dejanske prednosti oziroma po čem menijo, da so najbolj prepoznavni? ${ }^{\mathbf{1 2}}$

- Katere (vsaj tri) priložnosti za izboljšanje navedene v poročilu so po njihovem mnenju najkoristnejše za organizacijo?

- Katere nove kazalnike bodo dodatno uvedli v sistem svojih meritev na podlagi rezultatov in ugotovitev $\vee$ pilotnem projektu PRSPO?

Skupaj je bilo tako po izboru anketiranih navedenih 86 različnih prednosti, 84 priložnosti za izboljšanje in 55 kazalnikov oziroma aktivnosti, povezanih z meritvami. $\vee$ nadaljevanju se pri vsakem merilu kot primer navaja po en odgovor (po izboru avtorja) na posamezno vprašanje. Anketiranci so prejeli vse zbrane odgovore na vprašanja, kar predstavlja zametek baze dobrih praks in priložnosti za izboljšanje $v$ prizadevanjih za poslovno odličnost $v$ javni upravi.

Kljub temu, da je bil $v$ analizi ankete zajet le manjši vzorec vseh ugotovljenih prednosti in priložnosti za izboljšanje ${ }^{\mathbf{1 3}}$, lahko povzamemo nekatere skupne ugotovitve, ki jih opredelimo kot organizacijsko upravljavske izzive menedžmenta javne uprave; z njimi pa se je na nivoju posameznih upravnih organizacij težje spopasti, saj zahtevajo sistemski pristop in podporo ministrstev. Kot primer navajamo le tri:

Izboljšanje meritev - Ugotovitve zunanjih ocenjevalcev, kot so "skromni nabori kazalnikov..., kazalniki ne izkazujejo triletnih trendov..., ocenjevanje ustreznosti in učinkovitosti pristopa ni opredeljeno..., niso določeni kriteriji merjenja učinkov..." govorijo o nepopolnem sistemu objektivnih meritev, kar onemogoča spoznavanje resničnega stanja $\vee$ organizaciji. K rešitvi problema bi prispevala poglobljena analiza uporabljenih in predlaganih kazalnikov $\vee$ pilotnem

12 Anketiranci so najverjetneje navajali prednosti po merilih, kjer so zbrali največ točk.

$13 \mathrm{~V}$ vseh 14 poročilih prijaviteljev je bilo podanih več sto prednosti in priložnosti za izboljšanje, anketiranci so $v$ anketi navedli le tiste, ki so se jim zdele najpomembnejše. 
projektu ter oblikovanje nabora standardnih meril in kazalnikov za organe javne uprave (Nemec, 2004).

Primerjava z najboljšimi - Zunanji ocenjevalci večkrat ugotavljajo »odsotnost primerjav z RS in EU..., niso navedeni cilji najboljšega..., kako se analizirajo in vgrajujejo pozitivne izkušnje drugih«. V veliko pomoč bi bil javno objavljen referenčni register nabora kazalnikov in meril merjenja delovanja javne uprave, kjer bi bile objavljene povprečne, minimalne in maksimalne vrednosti posameznih kazalnikov. Objavljene bi bile tudi "dobre prakse" in pristopi tistih, ki pri posameznem kazalcu dosegajo najboljše rezultate. Osnova za to bazo bi lahko bile ugotovljene prednosti v okviru pilotnega projekta PRSPO (npr. pristopi ene izmed upravnih enot, ki je bila pri merilu "vpliv na družbo" edina uvrščena $v$ razred 301-400 točk).

Povezovanje ciljev organizacije z delovnimi mesti in ključnimi procesi $\checkmark$ priporočilih za izboljšave je večkrat navedeno "ni pristopa pri opredeljevanju osebnih ciljev in ciljev oddelkov..., osebni cilji se ne pregledujejo in usklajujejo $z$ organizacijskimi in strategijo «. Ključno vprašanje je, kako se spremlja in motivira zaposlene za doseganje ciljev in ali zaposleni sploh vidijo svoj prispevek pri doseganju skupnih ciljev. Priložnost za izboljšanje stanja je v skorajšnji uvedbi „Projekta učinkovitosti (MJU, predvidoma v letu 2006), ki omogoča na osnovi časovnih standardov za postopke $z$ istimi kazalniki informacijsko podprto merjenje osebne učinkovitosti zaposlenih, oddelkov in organizacije . 
Tomislav Nemec

\section{Izboljševanje poslovanja s pomočjo modela poslovne odličnosti}

\section{Preglednica 4: Primer prednosti, priložnosti izboljšanja in novega kazalnika glede na merilo ${ }^{14}$}

\begin{tabular}{|c|c|c|c|}
\hline merilo & prednost & priložnosti izboljšanja & nov kazalnik \\
\hline 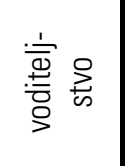 & $\begin{array}{c}\text { Vzpostavljen je sistematičen pristop k } \\
\text { preverjanju in izboljševanju učinkovi- } \\
\text { tosti vodenja (notranje presoje po } \\
\text { standardu ISO, samoocena po modelu } \\
\text { CAF, SiOK). }\end{array}$ & $\begin{array}{l}\text { Izboljšanje sistema neposrednega } \\
\text { vključevanja zaposlenih v procese } \\
\text { sprememb na področju dojemanja } \\
\text { poslanstva, vrednot, vizije in ciljev. }\end{array}$ & $\begin{array}{l}\text { Število izboljšav na } \\
\text { podlagi prepoznane } \\
\text { najboljše prakse. }\end{array}$ \\
\hline 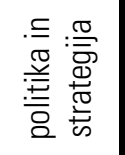 & $\begin{array}{c}\text { UE ima sprejeto politiko in strategijo } \\
\text { udejanjanja s procesnim pristopom in } \\
\text { sistemom vodenja s cilji. }\end{array}$ & $\begin{array}{c}\text { Ni razvidnega izmenjevanja naj- } \\
\text { boljših praks na tem področju oz. } \\
\text { drugih načinov izmenjevanja } \\
\text { znanja. }\end{array}$ & $\begin{array}{l}\text { Odstotek zaposlenih, ki } \\
\text { imajo pozitivno mnenje } \\
\text { glede uvedenega sis- } \\
\text { tema kakovosti. }\end{array}$ \\
\hline 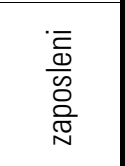 & $\begin{array}{l}\text { Vzpostavitev in delo odbora za zado- } \\
\text { voljstvo zaposlenih ter njegov vpliv na } \\
\text { izboljšanje medčloveških odnosov. }\end{array}$ & $\begin{array}{c}\text { Pristop na področju usklajevanja, } \\
\text { pregledovanja in posodabljanja } \\
\text { osebnih ciljev z organizacijskimi ni } \\
\text { jasno nakazan in izpeljan iz } \\
\text { splošne strategije. }\end{array}$ & $\begin{array}{l}\text { Odstotek uporabnih } \\
\text { predlogov izboljšav } \\
\text { zaposlenih. }\end{array}$ \\
\hline 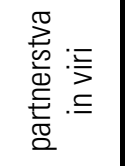 & $\begin{array}{c}\text { Na osnovi analiz vzrokov napak je UE } \\
\text { pričela vzpostavljati dialog z zunanjimi } \\
\text { partnerji glede izmenjave znanj, kar je } \\
\text { prispevalo k hitrejšemu reševanju } \\
\text { zadev. }\end{array}$ & $\begin{array}{l}\text { Aktivno spremljanje pričakovanj in } \\
\text { potreb partnerjev PU za izboljšave } \\
\text { izvedbenih procesov policije. }\end{array}$ & $\begin{array}{c}\text { Stopnja primernosti } \\
\text { dobavitelja }\end{array}$ \\
\hline $\begin{array}{l}\overline{\mathscr{d}} \\
\overline{0} \\
\text { 을 }\end{array}$ & $\begin{array}{c}\text { UE je vpeljala sistem ISO 9001:2000, } \\
\text { ki je osnovni procesni pogled in temelj } \\
\text { za nenehno izboljševanje. }\end{array}$ & $\begin{array}{c}\text { Ni dokazil o izmenjevanju dobre } \\
\text { prakse med UE pri uvajanju novih } \\
\text { upravnih postopkov na osnovi } \\
\text { zakonskih določil. }\end{array}$ & $\begin{array}{c}\text { Število sprememb } \\
\text { izvajanja procesov, } \\
\text { na podlagi predlogov } \\
\text { delovnih skupin ali } \\
\text { posameznikov }\end{array}$ \\
\hline 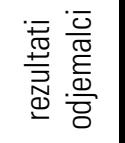 & $\begin{array}{l}\text { Odpravljen je bil čakalni čas pred } \\
\text { pisarnami. }\end{array}$ & $\begin{array}{l}\text { Uvesti spremljanje zadovoljstva } \\
\text { "nevidnih« odjemalcev npr. minis- } \\
\text { trstev, Iokalnih skupnosti, drugih } \\
\text { služb. }\end{array}$ & $\begin{array}{l}\text { Odstotek pohval od } \\
\text { vseh pripomb na delo } \\
\text { UE. }\end{array}$ \\
\hline 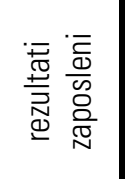 & $\begin{array}{l}\text { UE je v letu } 2004 \text { kot prva UE v državi } \\
\text { prejela certifikat Vlagatelji v ljudi. }\end{array}$ & $\begin{array}{l}\text { Skromen nabor kazalnikov - } \\
\text { odsotnost ključnih (usposoblje- } \\
\text { nost, produktivnost, nagrade, } \\
\text { timsko delo, odzivnost pri anketi- } \\
\text { ranju, nesreče, pritožbe, bonitete). }\end{array}$ & $\begin{array}{l}\text { Razpoložljivost : } \\
\text { št. opravljenih ur/ št. } \\
\text { planiranih ur. }\end{array}$ \\
\hline 坖 $\frac{0}{2}$ & $\begin{array}{c}\text { V sistemski dokumentaciji vodenja } \\
\text { kakovosti so opredeljene smernice, ki } \\
\text { opredeljujejo odnos do kakovosti življen- } \\
\text { ja, okolja in ohranjanja kulturnega } \\
\text { dialoga z drugimi upravnimi organi. }\end{array}$ & $\begin{array}{l}\text { Odsotnost anketiranja okolja o } \\
\text { družbeni vpetosti UE. }\end{array}$ & $\begin{array}{l}\text { Število vključevanj } \\
\text { UE v dejavnosti } \\
\text { lokalnih skupnosti in } \\
\text { družbenega okolja. }\end{array}$ \\
\hline 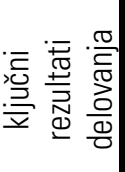 & $\begin{array}{l}\text { Iz prikazanih rezultatov je razvidna } \\
\text { racionalna poraba proračunskih } \\
\text { finančnih sredstev. }\end{array}$ & $\begin{array}{l}\text { Definiranje ključnih rezultatov } \\
\text { delovanja glede na sprejeto } \\
\text { "Strategijo razvoja javnega sek- } \\
\text { torja». }\end{array}$ & $\begin{array}{l}\text { Število neskladij, } \\
\text { ugotovljenih pri } \\
\text { zunanjih presojah in } \\
\text { nadzorstvenih pre- } \\
\text { gledih. }\end{array}$ \\
\hline
\end{tabular}

14 Navedena prednosti, priložnosti za izboljšanje in kazalniki pri posameznem merilu niso med seboj vsebinsko povezani in se ne nanašajo na isto podmerilo. 


\section{Zaključna misel}

Vsak model, tudi model odličnosti, je za organizacijo dober le toliko, kolikor dejansko vpliva na izboljšanje njenega poslovanja. Tudi sodelovanje $v$ pilotnem projektu PRSPO za javno upravo je smiselno predvsem zaradi povratne informacija $v$ obliki poročila, na podlagi katerega dobi vsaka organizacija obširne informacije o prednostih in priložnostih za izboljšanje. Prvi rezultati, vsaj za 14 sodelujočih, so spodbudni, prav tako so dokazani njihovi koristni učinki. Nagrada za sodelovanje pa je tudi spoznanje, da je trajno izboljšanje in doseganje dobrih rezultate možno le, če izboljšujemo tudi dejavnike. Za njihovo izboljševanje in za samo odličnost pa je potrebno veliko kreativnosti, znanja in vztrajnosti ali, kot je rekel mislec Aristotel: "Samo to, kar počnemo znova in znova. Odličnost ni eno samo dejanje, odličnost je navada". Koliko te "navade« je namenjeno slovenski javni upravi kot celoti, pa bo pokazal čas.

Tomislav Nemec je diplomiral na Ekonomski fakulteti v Mariboru. Zaposlen je kot načelnik na Upravni enoti Ljutomer ter je vključen $v$ delovne skupine za obvladovanje kakovosti na MJU. Z referati na temo kakovosti se udeležuje strokovnih srečanjih, $s$ svojimi prispevki pa poskuša povezovati praktične rešitve problemov kakovosti $v$ javni upravi s teoretičnimi izhodišči. V svojem raziskovalnem delu se ukvarja z oblikovanjem modela za ocenjevanje in merjenje kakovosti procesov $v$ javni upravi.

\section{Literatura in viri}

- EFQM (2004): Slovenski prevod "Ocenjevanje odličnosti - Praktični vodnik...", Urad RS za meroslovje, Ljubljana.

- Dolinšek, S. in drugi (2004): "Sistemi vodenja kakovosti za visokošolske zavode", Slovensko združenje za kakovost, Zbornik referatov, Portorož, str. 63-65.

- Grebenc, M. (2004): "Odličnost vodenja - sinergija različnih sistemov, modelov in pristopov iz različnih sektorjev in industrij", Slovensko združenje za kakovost, Zbornik referatov, Portorož, str. 32-34.

- Kern Pipan, K. in drugi (2004): „Pristopi za doseganje odličnosti - modela EFQM, CAF ter pilotni projekti PRSPO «, Slovensko združenje za kakovost, Zbornik referatov, Portorož, str 66-69.

- Ložar, B. (2003): „Primerjava sistemov vodenja v slovenskih podjetjih in multinacionalkah«, Slovensko združenje za kakovost, Zbornik referatov, Portorož, str. 37-38.

- Marolt, J., Gomišček, B. (2005): „Management kakovosti«, Založba moderna organizacija, Kranj, str. 526. 


\section{Tomislav Nemec}

\section{Izboljševanje poslovanja s pomočjo}

modela poslovne odličnosti

- Nemec, T (2004): »lzkaz in ocena uspešnosti s pomočjo večparametrskega modela ", XI. dnevi slovenske uprave - Zbornik referatov - zgoščenka, Fakulteta za upravo, Ljubljana.

- Pečar, Z. (2005): "Projekt: Učinkovitost upravnih enot - poročilo julij 2005«, interno gradivo Ministrstva za javno upravo, Ljubljana.

- Škafar, B. (2005): »Inovativnost in model poslovne odličnosti v komunalnem podjetju«, Pomurski ekološki center, Murska Sobota. 


\section{SUMMARY}

\section{Improving Business Operation by Means of the Business Excellence Model}

In recent years much effort has been undertaken by individual bodies in public administration with the aim of improving the quality of business operations and becoming as successful as possible (in other words, achieving business excellence). In Slovenian public administration, the field of quality is one of the rare fields which use standardized international management systems, such as $\mathrm{ISO}^{15}, \mathrm{CAF}^{16}$ and $\mathrm{EFOM}^{17}$. The mere fact that an administrative organisation has introduced one of the management models is relevant to the stakeholders only in so far as they themselves can "feel" a direct benefit from it. These models represent only the bases which have to be supplemented with good practices and approaches; furthermore, the following objective must be achieved: good (excellent) results in all fields. The permanent objective of Slovenian public administration must be the provision of services which will satisfy their users; these services will not only meet but also exceed customers' expectations in terms of expertise, efficiency and responsiveness. Through its own example the state has to contribute to the creation of a stimulating environment which will allow the "good" to become "excellent" and which will enable the "excellent" to become winners according to European standards as well.

In 2004, the EFOM pilot project for public administration was carried out in Slovenia in which 14 administrative organisations participated (13 administrative units and one police directorate). For the first time ever, the implementation of the EFOM pilot project provided independent external assessments of public administration bodies' operation which enables objective comparison of the efficiency of public administration and the economic sector. A condition for participation in the project was the ISO quality standard or at least a performed self-assessment process according to the CAF model. The results achieved were relatively good as the two best administrative units were classified in the $301-400$ points class, while the majority of applicants $(57.1 \%)$ fell into the $201-300$ points class, which, taking into account the results of the previous pilot project, represents a very good result. The EFOM pilot project provides an opportunity for the preparation of a comprehensive content analysis on the basis of the advantages identified and opportunities for improvement and for drawing up recommendations and guidelines for further public administration development towards business

\footnotetext{
${ }^{15}$ International Organisation for Standardization

${ }^{16}$ Common Assessment Framework

${ }^{17}$ European Foundation for Quality Management
} 
Tomislav Nemec

Izboljševanje poslovanja s pomočjo

modela poslovne odličnosti

excellence. How can a set of innovative ideas, new proposals, improvements and legal measures which will be effective and will move organisations a step higher on their way towards excellence be achieved? These issues are not of interest solely to public administration management but they also represent a challenge for other organisations. What needs to be introduced in public administration is a responsibility toward innovation; in addition, carefully planned encouragement of creativity should be initiated and broad communication channels must be established through which all unresolved problems and issues and proposed solutions will be presented. A challenge for public administration has thus arisen, namely the establishment of an "innovative" internal culture. Public administration has to provide conditions in which the innovative process will be defined and controlled and in which creative thinking becomes an important value, rule and activity.

With the aim of promoting communication and the sharing of at least some key findings from individual reports prepared by external assessors, a survey was carried out among all the participants in the PRSPO pilot project (Business Excellence Prize of the Republic of Slovenia - PRSPO) in 2005. The central part of the paper presents the summary assessments of external assessors. Provided for each of the model's criteria is an example of the advantages identified, an example of opportunities for improvement and an example of a new indicator. These examples have been chosen from among the findings which participants in the survey considered to be of most benefit to them. The paper also presents the measures which the Administrative Unit Ljutomer, on the basis of the feedback assessment, included in the 2005 Annual Plan. Despite the fact that only a small sample of all advantages and opportunities for improvement were included in the survey analysis, it is still possible to summarise some common findings which can be defined as organisational and managerial challenges for public administration management that are very difficult to tackle at the level of individual administrative organisations since they require a systematic approach and the support of the ministries. These challenges are as follows:

- improvement of performance measurement management;

- possibility for mutual comparison and the establishment of a best practice database;

- integration of organisation objectives, workplaces and key processes.

Let me conclude this paper with the idea that any model, including the excellence model, is good for an organisation only in so far as it actually works toward the improvement of its business operation. Improvement and excellence require a great deal of creativity, knowledge and persistency, or, as the great philosopher Aristotle put it: "We are what we repeatedly do. Excellence, therefore, is not an act but a habit". 